University of Wollongong

Research Online

Faculty of Engineering and Information

Faculty of Engineering and Information

Sciences - Papers: Part A

Sciences

$1-1-2015$

\title{
Coal seam gas produced water treatment by ultrafiltration, reverse osmosis and multi-effect distillation: a pilot study
}

Long D. Nghiem

University of Wollongong, longn@uow.edu.au

Christian Elters

University of Wollongong, ce654@uowmail.edu.au

Alexander Simon

University of Wollongong, asimon@uow.edu.au

Taguchi Tatsuya

Sasakura Engineering Co. Ltd

William Price

University of Wollongong, wprice@uow.edu.au

Follow this and additional works at: https://ro.uow.edu.au/eispapers

Part of the Engineering Commons, and the Science and Technology Studies Commons

Research Online is the open access institutional repository for the University of Wollongong. For further information contact the UOW Library: research-pubs@uow.edu.au 


\title{
Coal seam gas produced water treatment by ultrafiltration, reverse osmosis and multi-effect distillation: a pilot study
}

\author{
Abstract \\ This study evaluates the technical feasibility of a pilot treatment train of ultrafiltration, reverse osmosis \\ (RO), and multi-effect distillation (MED) for coal seam gas (CSG) produced water treatment. A total of \\ $12,000 \mathrm{~L}$ of CSG produced water was processed from the Gloucester Basin in New South Wales \\ (Australia). The results demonstrate the technical feasibility to obtain an overall clean water recovery of \\ $95 \%$ and a final brine containing mostly sodium bicarbonate up to of $48 \mathrm{~g} / \mathrm{L}$. Stable operations of the pilot \\ RO and MED systems at $76 \%$ and $80 \%$ recovery, respectively, were achieved. The results show that anti- \\ scalant addition could effectively prevent scaling during MED operation. Mass balance analysis and \\ analytical measurement suggest that precipitation of calcium, magnesium and silica might have \\ occurred. Indeed, mineral deposition on the sight glass of the MED evaporative chamber became visible \\ after 3 days of continuous operation. However, no evidence of mineral precipitation or scaling could be \\ observed on the evaporative tubes of the MED system. In addition, the mineral deposition on the sight \\ glass was completed removed by chemical cleaning at the end of the pilot evaluation program. The \\ obtained RO permeate and MED distillate were of high quality and could be blended with UF filtrated CSG \\ produced water for irrigation to reduce the treatment demand.

\section{Disciplines} \\ Engineering | Science and Technology Studies

\section{Publication Details} \\ Nghiem, L. D., Elters, C., Simon, A., Tatsuya, T. \& Price, W. (2015). Coal seam gas produced water \\ treatment by ultrafiltration, reverse osmosis and multi-effect distillation: a pilot study. Separation and \\ Purification Technology, 146 94-100.
}



reverse osmosis and multi-effect distillation: a pilot study

5 Long D. Nghiem ${ }^{1} *$, Christian Elters ${ }^{1}$, Alexander Simon ${ }^{1}$, Taguchi Tatsuya ${ }^{2}$, and William Price ${ }^{3}$ University of Wollongong, Wollongong, NSW 2522, Australia

13 * Corresponding author: Long Duc Nghiem, Email longn@uow.edu.au; Tel: +61 242214590 


\section{Abstract}

15 This study evaluates the technical feasibility of a pilot treatment train of ultrafiltration, reverse 16 osmosis (RO), and multi-effect distillation (MED) for coal seam gas (CSG) produced water 17 treatment. A total of 12,000 L of CSG produced water was processed from the Gloucester Basin 18 in New South Wales (Australia). The results demonstrate the technical feasibility to obtain an 19 overall clean water recovery of $95 \%$ and a final brine containing mostly sodium bicarbonate up 20 to of $48 \mathrm{~g} / \mathrm{L}$. Stable operations of the pilot RO and MED systems at 76 and $80 \%$ recovery, 21 respectively, were achieved. The results show that anti-scalant addition could effectively prevent 22 scaling during MED operation. Mass balance analysis and analytical measurement suggest that 23 precipitation of calcium, magnesium and silica might have occurred. Indeed, mineral deposition 24 on the sight glass of the MED evaporative chamber became visible after 3 days of continuous 25 operation. However, no evidence of mineral precipitation or scaling could be observed on the 26 evaporative tubes of the MED system. In addition, the mineral deposition on the sight glass was

27 completed removed by chemical cleaning at the end of the pilot evaluation program. The 28 obtained RO permeate and MED distillate were of high quality and could be blended with UF 29 filtrated CSG produced water for irrigation to reduce the treatment demand.

30 Keywords: Coal seam gas (CSG) produced water, reverse osmosis (RO), multi-effect distillation 31 (MED), brine minimisation, and scaling. 


\section{Introduction}

33 Coal seam gas (CSG), which is also known as coal bed methane (CBM), is a form of natural gas.

34 CSG is essentially methane and can be used in the same way as conventional gas. Unlike coal

35 and petroleum oil, the global distribution of CSG is geographically dispersed. Significant CSG

36 reserves have been identified in Australia, Canada, China, Eastern Europe, India, and the USA

$37[1-3]$.

As a notable example, Australia has seen some of the most significant CSG developments in the world [4]. Australia is on track to become the world's largest liquefied natural gas (LNG) producer by about 2018 [2]. It is estimated that $70 \%$ of the global LNG capacity under construction is taking place in Australia to tap into its vast CSG reserve [2]. CSG also plays an important role in the domestic market. CSG is expected to supply at least $30 \%$ of the Australian domestic energy market by 2030. CSG developments in New South Wales and Queensland will potentially contribute $78 \%$ of natural gas reserves in the eastern states [5].

Electricity generation from natural gas emits significantly less greenhouse gases and air pollutants than coal. According to the US EPA Emissions \& Generation Resource Integrated Database, natural gas produces only 50,33, and $1 \%$ of carbon dioxide, nitrogen oxides, and sulfur oxides at the power plant, respectively, compared to coal-fired electricity generation. Thus, CSG is expected to play a major role in the global energy mix to lessen the impact of fossil fuel on global warming and the environment while renewable energy is being developed [2].

CSG exists in almost all underground coal seams (typically 300-600 m below the surface) where it adsorbs to coal matrix and is held in place by water pressure. Groundwater extraction is required to depressurise the target coal seams and allow CSG to flow to the surface. Thus, CSG extraction usually involves the co-production of water, known as CSG produced water [6].

CSG produced water is essentially saline groundwater. The actual composition and volume of CSG produced water varies greatly from one region to another [3, 7]. In Australia, CSG produced water consists predominantly of sodium, bicarbonate $\left(\mathrm{HCO}_{3}{ }^{-}\right)$, and chloride. Due to the high salt content, direct discharge of CSG produced water to inland water bodies may entail a range of adverse effects to the environment [1,8]. For example, because of the high sodium content, the use of untreated CSG produced water for irrigation can lead to a gradual decrease in the permeability of soil, eventually causing infiltration problems and other form of soil 62 degradation [9]. 
63 The state-of-the-art technology for CSG produced water management currently includes pre64 treatment (e.g. coagulation, $\mathrm{pH}$ adjustment, ultra- (UF) or micro filtration) and reverse osmosis 65 (RO) $[4,6,10]$. RO can achieve about 75\% water recovery, depending on the salinity (hence osmotic pressure) and the fouling potential of the CSG produced water. RO also produces a

67 volume of even more concentrated CSG produced water called brine [11]. RO brine is a major challenge for the sustainable produced water management in the CSG industry [6]. In Australia, this RO brine is usually stored in evaporation ponds. However, the use of evaporation ponds is costly and is only a temporary measure. For new developments the use of evaporation basins is unlawful in most states unless there are no alternative solutions. Given the possible leakages of the brine into the environment, regulators in Australia have actively encouraged the CSG industry to phase out the use of evaporation ponds for CSG RO brine storage [4]. This policy has encouraged several recent attempts to develop techniques to reduce the volume and/or to beneficially extract the minerals from CSG RO brine $[4,12,13]$. A noteworthy example is the recovery of soda ash from the CSG RO brine, which is being developed by Penrice (Penrice Soda Holdings Limited, Australia) in collaboration with GE (General Electric, Australia) and QGC (QGC Pty Limited, Australia). Another possibility is to use the sodium rich brine as feedstock to profitable generate sodium hydroxide by membrane electrolysis [14]. Both of these approaches require the CSG RO brine to be further concentrated to as close to saturation as possible to reduce downstream processing cost. Given the high osmotic pressure and scaling potential of CSG RO brine, the use of several thermal separation processes such as multi-effect distillation (MED) and membrane distillation to undertake this additional concentration step have been suggested in the literature [3]. These processes consume primarily thermal energy and thus they can be readily integrated with a solar thermal collection system. Indeed, solar-assisted MED systems for seawater and brackish water desalination have been demonstrated in several recent studies $[15,16]$. However, to date, the technical feasibility of MED to further concentrate CSG RO brine has not been systematically investigated either at laboratory or pilot scale level.

This study aims to evaluate the use of UF, RO and MED at pilot scale level for CSG produced 90 water treatment with respect to process stability and scaling potential. In addition, permeate, 91 distillate and brine chemistries as well as possible process optimisations were reported and 92 discussed. 


\section{$93 \quad 2 \quad$ Materials and Methods}

\section{$94 \quad 2.1 \quad$ Pilot treatment train}

95 The pilot treatment train consisting of UF pre-treatment, RO filtration, and MED used in this

96 study is shown in Figure 1. The UF and RO systems (Figure 1b) were constructed by OsmoFlo

97 (Adelaide, SA, Australia) specifically for pilot evaluation purposes and were housed in a $20 \mathrm{ft}$

98 shipping container. The UF system consisted of two hollow fibre polyacrylonitrile UF membrane

99 modules (Ultra-Flo U860 Cartridge), each with a total membrane surface area of $96.6 \mathrm{~m}^{2}$. The

100 UF membrane had a nominal pore size of $25 \mathrm{~nm}$ and permeability at $20{ }^{\circ} \mathrm{C}$ of $93 \mathrm{~L} / \mathrm{m}^{2} \mathrm{hbar}$. The

101 RO system was equipped with three 4-inch brackish water membrane modules (AG4040FM,

102 General electrics, USA), each with an active membrane surface area of $23.7 \mathrm{~m}^{2}$. The nominal

$103 \mathrm{NaCl}$ rejection and water permeability of the RO membrane was $99.5 \%$ and $3.09 \mathrm{~L} / \mathrm{m}^{2} \mathrm{hbar}$ (at

$10425^{\circ} \mathrm{C}$ and $2 \mathrm{~g} / \mathrm{L} \mathrm{NaCl}$ ), respectively. Two cartridge filters ( 2 x 20” $\mathrm{BB}$ ) with pore size of $1 \mu \mathrm{m}$

105 were installed before the RO membrane modules for their protection from accidental intrusion of

106 small objects or suspended solids to the feed reservoir. This is the standard design in an

107 industrial RO system.

108 The pilot MED system (Figure 1c) was designed and constructed by Sasakura Engineering Co., 109 (Osaka, Japan). It consisted of a heating chamber, an evaporating chamber, and a condenser. The 110 system was equipped with a supervisory control and data acquisition (SCADA) system, and thus, 111 was fully automated. 

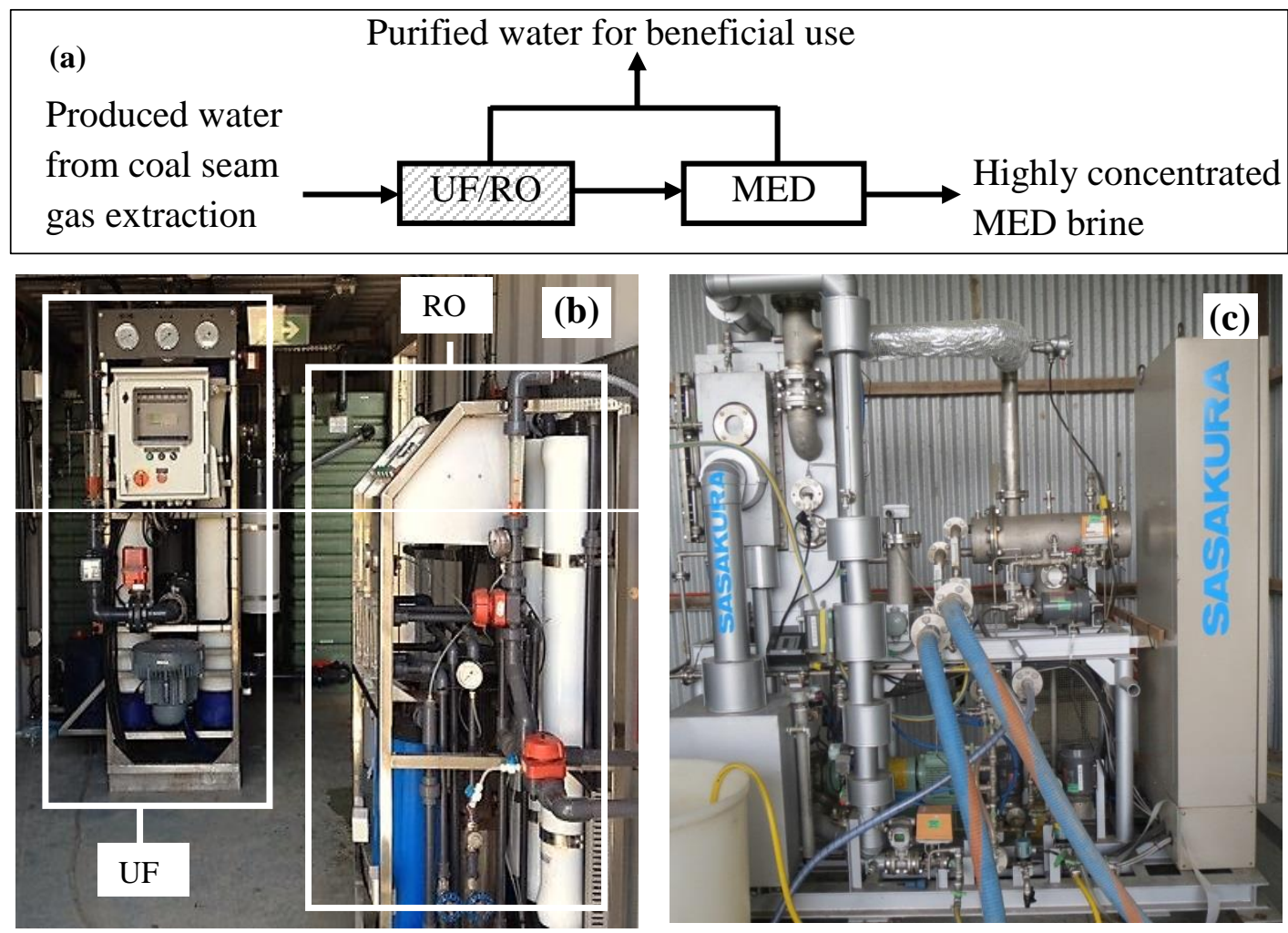

113 Figure 1: (a) Process diagram, (b) the pilot UF and RO system, c) the MED system.

\section{$114 \quad 2.2 \quad$ Experimental protocol}

115 CSG produced water was collected and used immediately from a pilot gas well in the Gloucester

116 Basin located along the lower north coast of New South Wales (Australia). The produced water

117 was from a gas well known as Waukivory 03, which was being flow tested to assess gas

118 production and the variability in produced water quality [17]. This CSG gas field is in a coal

119 basin, generally described as part of the Hunter Coalfields or the Northern Sydney Basin [18].

120 The UF system was operated in the dead end mode. Each filtration cycle consisted of 17 minutes

121 of production, followed by 40 seconds of air scouring and 30 seconds of back-flushing. The

122 trans-membrane pressure of the UF was below 0.55 bar to prevent any irreversible membrane

123 blocking. An industrial grade anti-scalant (Osmotreat, Osmoflo, Adelaide, SA, Australia) was

124 added to the UF filtrate to obtain $5 \mathrm{mg} / \mathrm{L}$ prior to $\mathrm{RO}$ filtration. The feed flow rate to the RO

125 system was $1 \mathrm{~m}^{3} / \mathrm{h}$ and the transmembrane pressure was set at 17 bar to obtain $76 \%$ water

126 recovery, which is comparable to a full scale system typically deployed for CSG produced water

127 treatment. The RO brine was fed into the MED system via an equalising tank. 
The MED system was operated continuously throughout the pilot program. The temperature and absolute pressure in the evaporative chamber were $70 \pm 2{ }^{\circ} \mathrm{C}$ and $25 \pm 1 \mathrm{kPa}$, respectively. Two anti-scalants, namely Belgard EV2030 (BWA, USA) and Accent 1131 (DOW Chemical, USA), were added to the RO brine to obtain 5 and $10 \mathrm{mg} / \mathrm{L}$ each, respectively. The RO brine feed flow rate to the MED system was $20 \mathrm{~L} / \mathrm{h}$ and water recovery was set at $80 \%$. This set point was selected to achieve an overall recovery of $95 \%$ from CSG produced water.

At the conclusion of the pilot program, as a precautionary measure, the evaporative chamber of the MED system was chemically cleaned with $30 \mathrm{~L}$ sulfamic acid $(0.3 \mathrm{M})$ followed by $30 \mathrm{~L}$ sodium hydroxide $(0.9 \mathrm{M})$. Each cleaning solution was circulated for 1 hour at $60{ }^{\circ} \mathrm{C}$ and followed by a rinsing step using distillate water.

\subsection{Analytical methods}

\subsubsection{Total organic carbon and bicarbonate}

Total carbon (TC) and total organic carbon (TOC) was analysed using a Shimadzu TOC/TN$\mathrm{V}_{\mathrm{CSH}}$ analyser (Shimadzu, Japan, Kyoto). The TOC measurement was conducted by acidifying the sample to $\mathrm{pH} 1.5$ using hydrochloric acid and subsequently air sparging for 5 minutes to remove all inorganic carbon in the form of carbonate. The bicarbonate concentration was calculated from the measured TC, TOC and the individual sample $\mathrm{pH}$ using a Bjerrum plot for carbonate systems [19].

\subsubsection{Anion analysis}

The concentrations of anions were determined using an Ion Chromatography system (LC-20AC, Shimadzu, Japan). The IC system was equipped with a Dionex Ion Pac AS23 anion-exchange column (Thermo Scientific, USA). The eluent consisted of $4.5 \mathrm{mM} \mathrm{Na} \mathrm{CO}_{3}$ and $0.8 \mathrm{mM}$ $\mathrm{NaHCO}_{3}$. The sample injection volume and eluent flow rate were $10 \mu \mathrm{m}$ and $1 \mathrm{~mL} / \mathrm{min}$, respectively. The system was calibrated using standards of 5, 10, 50 and $100 \mathrm{mg} / \mathrm{L}$ of each ion.

\subsubsection{Cation analysis}

An Agilent 7500 CS (Agilent Technologies, Wilmington, DE, USA) inductively-coupled plasma mass spectrometer (ICP-MS) was used to measure the concentrations of Boron, $\mathrm{Mn}^{2+}, \mathrm{Al}^{2+}, \mathrm{Na}^{2+}$, $\mathrm{K}^{+}, \mathrm{Mg}^{2+}, \mathrm{Ca}^{2+}$ and $\mathrm{Fe}^{2+}$. The samples were diluted with $2 \%$ Suprapur nitric acid. The ICP-MS was tuned prior to each analysis batch by using a multi-element tuning solution, containing 10 
$\mu \mathrm{g} / \mathrm{L}$ of $\mathrm{Li}, \mathrm{Y}, \mathrm{Ce}, \mathrm{Tl}$ and $\mathrm{Co}[20]$. Triplicate analysis was conducted, and the variations were always less than $5 \%$.

\subsubsection{Other water quality parameters}

Silica $\left(\mathrm{SiO}_{2}\right)$ concentration was measured using a Pocket Colorimeter II (Hach, Colorado, USA). Samples from RO and MED brine were diluted up to 10 times using Milli-Q water to avoid possible interferences from the high salinity of the sample. The silt density index (SDI) of the raw CSG produced water and UF filtrate was measured based on the standard method D4189. Turbidity was measured using a Hach 2100Qis portable turbidity meter (Hach, Colorado, USA). Conductivity and $\mathrm{pH}$ were measured using an Orion star A325 portable $\mathrm{pH} /$ conductivity meter (Thermo Scientific, USA).

\section{Results and discussion}

\subsection{Water characteristics}

The CSG produced water used in this study was slightly brackish (Table 1). Sodium (1,351 mg/L) and bicarbonate $(1,717 \mathrm{mg} / \mathrm{L})$ were the two dominating ionic species in this CSG produced water. Concentrations of other common cations and anions in this CSG produced water were either very low or undetectable. In particular, the chloride concentration of $62.2 \mathrm{mg} / \mathrm{L}$ is significantly lower than that reported from other CSG fields in Queensland (Australia) [6]. The concentrations of calcium and magnesium are also insignificant, possibly due to a hydro-chemical process along the groundwater flow path and the old age of this produced water (Table 1). The high sodium adsorption ratio value (SAR) of 89.6 of this CSG produced water renders it unusable for irrigation without dilution, treatment or chemical amendment. The organic content of this CSG produced water is very low $(1.7 \mathrm{mg} / \mathrm{L})$. Thus, the propensity of organic fouling associated with this CSG produced water is negligible. The high turbidity (32 NTU) and $\mathrm{SDI}_{15}$ value (6.3) of this CSG produced water (Table 1) could be attributed to its high iron content. Further details of this CSG produced water are available elsewhere [17]. It is noteworthy that iron precipitate was observed a few hours after the CSG produced water was extracted to the surface. When CSG produced water is brought to the surface, due to the oxidation of ferrous into ferric which forms a precipitate, the dissolved iron content of the CSG produced water is relatively low. Nevertheless, the high turbidity and $\mathrm{SDI}_{15}$ value reported here suggest that this CSG produced water cannot be fed directly to the RO process. Aeration is recommended to ensure complete removal of dissolved iron prior to membrane filtration. 
Table 1: Characteristics of the CSG produced water.

\begin{tabular}{|l|l|}
\hline \multicolumn{2}{|c|}{ General characteristics } \\
\hline Conductivity & $4.449 \mathrm{mS} / \mathrm{cm}$ \\
\hline Turbidity & $32 \mathrm{NTU}$ \\
\hline pH & 8.4 \\
\hline Total organic carbon & $1.7 \mathrm{mg} / \mathrm{L}$ \\
\hline SAR & 89.6 \\
\hline Silt density index $\left(\mathrm{SDI}_{15}\right)$ & 6.3 \\
\hline \multicolumn{2}{|c|}{ Ion concentration $(\mathbf{m g} / \mathrm{L})$} \\
\hline Bicarbonate & 1717.4 \\
\hline Chloride & 62.2 \\
\hline Sodium & 1351.2 \\
\hline Magnesium & 4.8 \\
\hline Potassium & 29.0 \\
\hline Calcium & 26.5 \\
\hline Iron & 43.6 \\
\hline Silica & 18.0 \\
\hline
\end{tabular}

\subsection{Water balance of the combined UF-RO-MED treatment train}

The overall water balance of this pilot programme is shown in Figure 2. Water recovery of the UF/RO process was set at $76 \%$. The RO brine was fed to the MED process to obtain an additional water recovery of $80 \%$, resulting in a total recovery of $95 \%$. The overall treatment efficiency in term of conductivity removal is also summarised in Figure 2. A total of 12,000 L of CSG produced water was treated in this pilot study. The performances of the individual processes in this treatment train are discussed in the subsequent sections.

Purified water $(95.2 \%$ at $0.05 \mathrm{mS} / \mathrm{cm})$

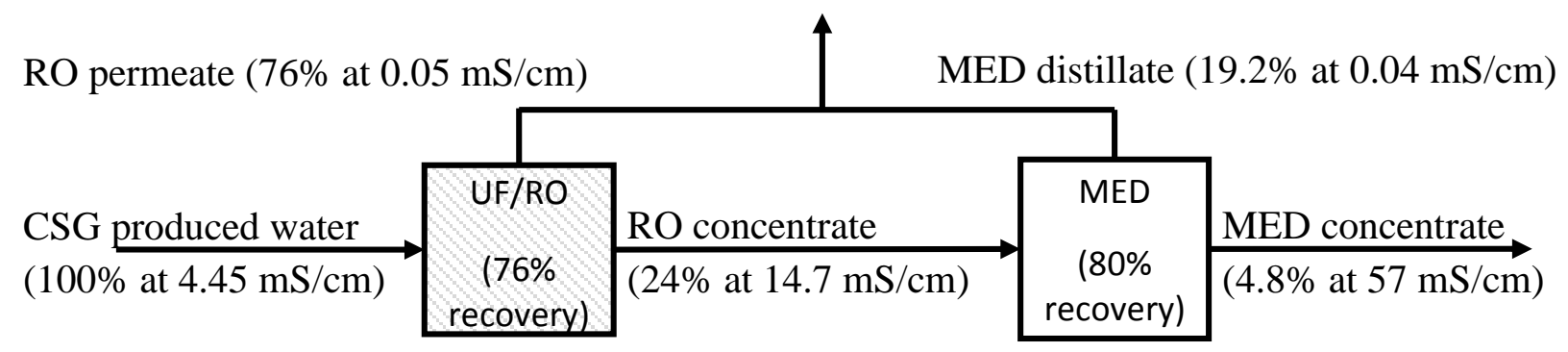

Figure 2: Water balance of this pilot study.

\subsection{Process stability}

During the pilot program, no discernible reduction in the water production rate was observed with the UF/RO and MED process (Figure 3). The automatic air-scoring and backwashing cycle described in section 2.2 was able to maintain the UF permeate flux at about $50 \mathrm{~L} / \mathrm{m}^{2} \mathrm{~h}$ (Figure 3a). 
UF pre-treatment reduced the CSG produced water turbidity from 32 NTU to less than 0.5 NTU. However, $\mathrm{SDI}_{15}$ of the UF treated CSG water was only reduced to 4.8. Despite this high $\mathrm{SDI}_{15}$ value after UF pre-treatment, no flux decline was observed with the RO process. Results reported here suggest that the $\mathrm{SDI}_{15}$ value may not be a suitable parameter to measure fouling propensity in RO applications for CSG produced water treatment. The results also indicate the effectiveness of the added anti-scalant to the UF filtrate.
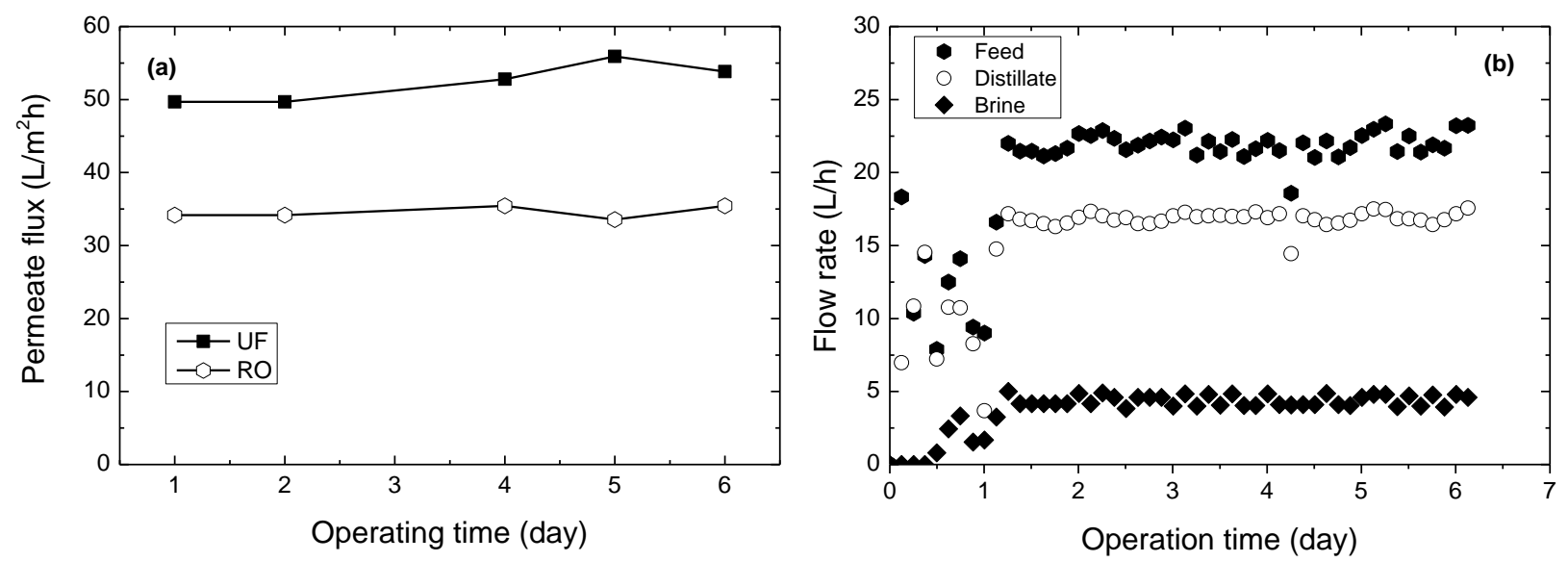

208

209

210

211

212

213

214

215

216

217

218

219

220

221

222

223

224

Figure 3: (a) Permeate flux of the UF and RO system and (b) Feed, distillate and brine flow rate of the MED system as a function of time.

Operation of the MED system was fully automated. Except the first day of operation, the flow rates of the feed (i.e. RO brine), distillate, and MED brine were constant throughout this pilot testing program (Figure 3b). Results from Figure 3b suggest that the addition of anti-scaling reagents to the MED feed (i.e. CSG RO brine) could effectively prevent the formation of any scale on the evaporative tubes. Overall, the results from Figure 3 show that a treatment train of UF, RO and MED could recover over $95 \%$ water from CSG produced water, without any notable evidence of fouling or scaling.

\subsection{Scaling assessment and effectiveness of chemical cleaning}

The risk of RO and MED scaling can also be assessed by comparing the analytically measured concentrations of mineral salts to those obtained from a mass balance calculation. As expected, the concentrations of all mineral salts in the RO permeate and MED distillate are either negligible or below the detection limits (Table 2). The measured concentrations of monovalent ions such as $\mathrm{Na}^{+}, \mathrm{Cl}^{-}, \mathrm{K}^{+}$are consistent with values from mass balance calculation. On the other hand, the measured concentrations of $\mathrm{Mg}^{2+}$ and $\mathrm{Ca}^{2+}$ in the MED brine are 186 and 680\% lower, 
225 respectively, than values obtained from mass balance calculation (Table 2). A similar 226 observation can also be seen with silica. The calculated mass balance of $\mathrm{SiO}_{2}$ closely matches

227 the measured value during RO. However, there is a significant deficit of $210 \%$ of $\mathrm{SiO}_{2}$ during 228 MED.

229 Table 2: Distribution of key elements in within the treatment train $(\mathrm{mg} / \mathrm{L})$.

\begin{tabular}{|c|c|c|c|c|c|c|c|}
\hline \multicolumn{2}{|r|}{ Elements } & $\mathrm{Na}^{+}$ & $\mathrm{Cl}^{-}$ & $\mathrm{Mg}^{2+}$ & $\mathrm{K}^{+}$ & $\mathrm{Ca}^{2+}$ & $\mathrm{Si}$ \\
\hline \multicolumn{2}{|l|}{ UF Filtrate } & 1165 & 67 & 4 & 14 & 34 & 18 \\
\hline \multirow{2}{*}{$\begin{array}{l}\text { RO brine } \\
\text { ( } 76 \% \text { recovery) }\end{array}$} & Mass balance & 4832 & 279 & 17 & 58 & 142 & 75 \\
\hline & Analytically measured & 4450 & 187 & 13 & 39 & 140 & 68 \\
\hline \multicolumn{2}{|l|}{ RO permeate } & 7 & 0 & 0 & 0 & 0 & 0 \\
\hline \multirow{2}{*}{$\begin{array}{l}\text { MED brine } \\
\text { ( } 80 \% \text { recovery) }\end{array}$} & Mass balance & 22238 & 935 & 65 & 195 & 700 & 340 \\
\hline & Analytically measured & 21242 & 798 & 21 & 154 & 25 & 108 \\
\hline \multicolumn{2}{|l|}{ MED distillate } & 3 & 0 & 0 & 0 & 0 & 0 \\
\hline
\end{tabular}

231 The deficit of $\mathrm{Mg}^{2+}, \mathrm{Ca}^{2+}$, and $\mathrm{SiO}_{2}$ in the MED brine suggests that some precipitates involved 232 these minerals have been formed. In fact, on the third day of MED operation, some precipitate 233 deposition was observed on the sight glass (Figure 4). By the end of the pilot testing program, 234 the entire sight glass was observed with a thin layer of mineral precipitates (Figure 4c). The 235 formation of a thin layer of precipitate on the sight glass can be attributed to the high affinity of 236 silica to glass, which also contains a large portion of $\mathrm{SiO}_{2}$ in its chemical composition.

237 It is noteworthy that no evidence of scaling on the evaporative tubes could be observed when the 238 evaporative chamber was inspected at the end of the pilot program. This observation is consistent 239 with the very low concentration of sparingly soluble minerals in the RO brine (Table 2).

240 Chemical cleaning using $0.3 \mathrm{M}$ sulfamic acid followed by $0.9 \mathrm{M}$ sodium hydroxide was 241 conducted and the thin layer of mineral deposition on the sight glass was completed removed 242 (Figure 4d). While scale was not observed in this pilot program, it is prudent to note that scaling 243 may still develop during an extended MED period of operation. Nevertheless, results reported 244 here also demonstrate that scaling can be effectively controlled by preventative chemical 245 cleaning. 

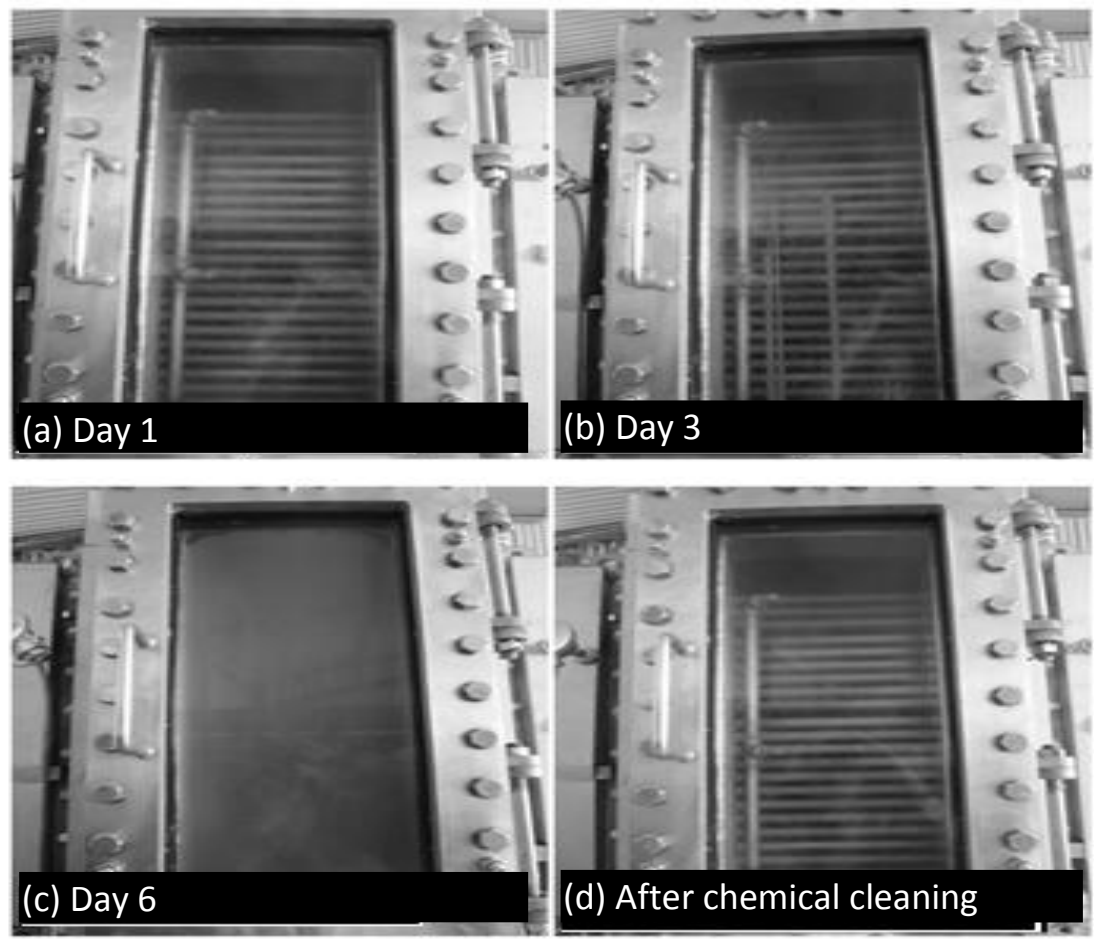

247 Figure 4: Mineral deposition on the sight glass of the MED evaporator. (a) at the beginning of 248 the process, (b) after 3 days of operating the MED, (c) at the end of the process, and (d) after 249 chemical cleaning using $0.3 \mathrm{M}$ sulfamic acid followed by $0.9 \mathrm{M}$ sodium hydroxide.

\section{$250 \quad 3.5$ Produced water and brine quality during the process}

\section{$251 \quad$ 3.5.1 Total dissolved solids}

252 The total dissolved solid (TDS) content of CSG produced water varies from one coal seam to 253 another and TDS concentrations from $0.01 \mathrm{~g} / \mathrm{L}$ up to $300 \mathrm{~g} / \mathrm{L}$ have been reported. In Australia, 254 typical TDS concentration of CSG produced water from coal seam range between $1-6 \mathrm{~g} / \mathrm{L}$ [6]. 255 The TDS of the produced water used in this pilot study was $2.51 \mathrm{~g} / \mathrm{L}$ and consisted mainly of 256 sodium and bicarbonate (Table 1). No impact on the TDS concentration by UF was observed in 257 this study. On the other hand, the rejection of TDS by RO and MED was 94.4 and 100\%, 258 respectively. Therefore, the TDS concentration of the RO and MED brine increased proportional 259 to the water recovery or concentration ratio (Figure 6). At a water recovery of 74\% using RO, 260 TDS concentration in the brine increased from 2.51 to $9.61 \mathrm{~g} / \mathrm{L}$. A further $80 \%$ water extraction 261 by the MED process produced in a final brine solution containing $48.41 \mathrm{~g} / \mathrm{L}$ TDS, resulting in 262 the overall fresh water recovery of $95 \%$.

263 In this study, the conductivity of the raw produced water was $4.449 \mathrm{mS} / \mathrm{cm}$ (Table 1), and UF 264 filtration had no impact on the water conductivity (Figure 5a). RO filtration and MED distillation 
resulted in a stable conductivity rejection of $99.7 \%$ and $99.9 \%$ throughout the study, respectively 266 (Figure 5a). Consequently, the increase in conductivity in the RO and MED brine was 267 proportional to the water recovery (i.e. concentration ratio). It is noteworthy that although the 268 MED process accounted only in $19.2 \%$ of the total process water recovery (Figure 2), it 269 increased the brine conductivity most notably by $71 \%$ (Figure 5a).
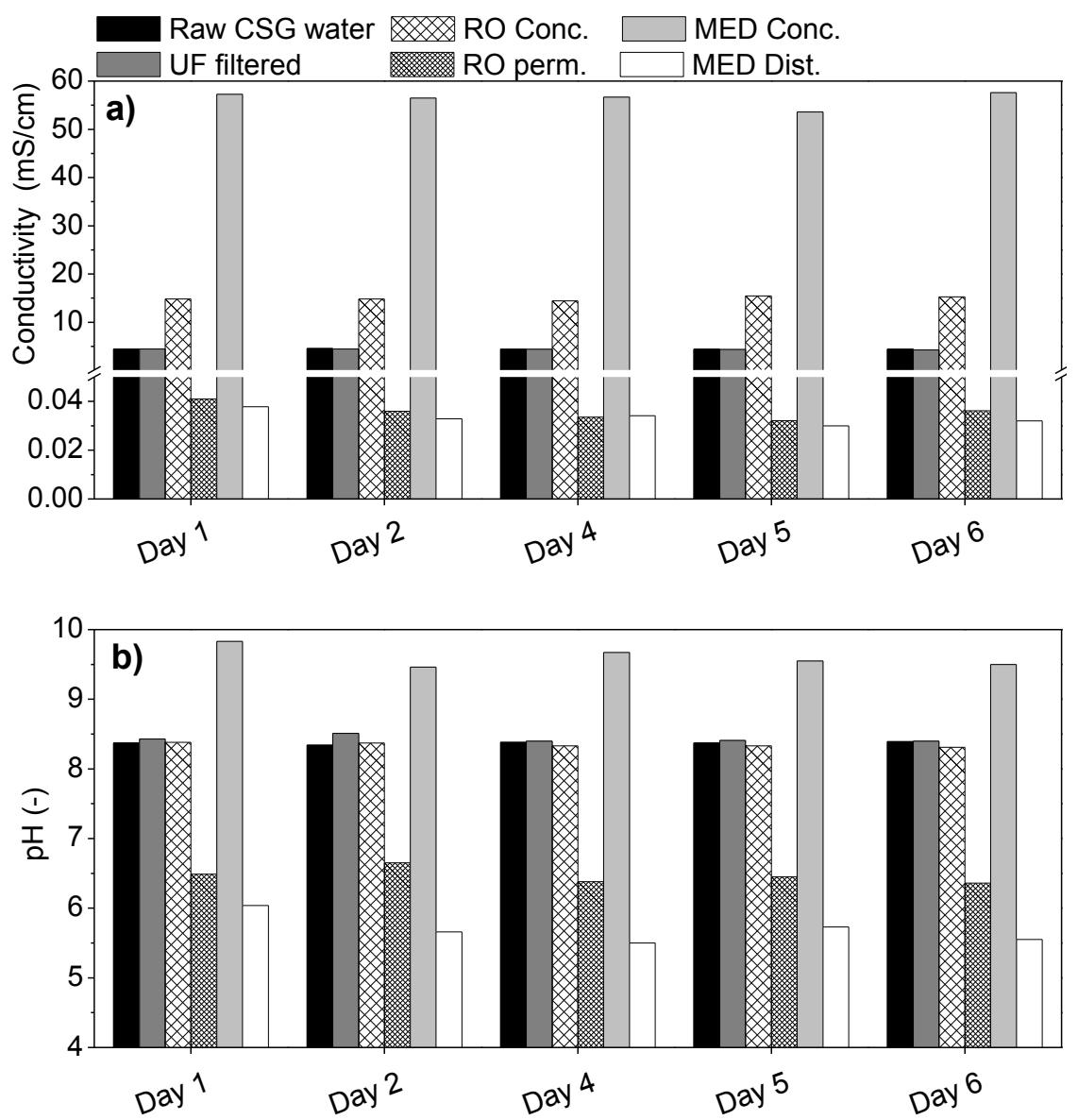

271 Figure 5: Impact of UF, RO and MED treatment on a) conductivity and b) pH of the CSG water brine 272 over six successive operating days. No data on day 3 were taken.

273 While UF filtration and subsequent concentration by $\mathrm{RO}$ had no impact on $\mathrm{pH}$ of the brine, a 274 significant increase in the $\mathrm{pH}$ of the brine solution was observed following the MED process 275 (Figure 5b). The $\mathrm{pH}$ of produced water depends on the ratio of acid and base components in the 276 solution and therefore, the increase in MED brine $\mathrm{pH}$ can be associated to enhanced degassing of 277 carbon (in the form of $\mathrm{CO}_{2}$ ) from the brine. Due to the high MED process temperature (i.e. $27870^{\circ} \mathrm{C}$ ), and likely supported by the low vacuum (i.e. $25 \mathrm{kPa}$ ), more $\mathrm{CO}_{2}$ can evaporate, which 279 resulted in a shift of the solution $\mathrm{pH}$ towards a more basic condition. By contrast, the absorption 280 of carbon dioxide, which forms carboxylic acid, to the RO permeate and MED distillate can shift 
the solution $\mathrm{pH}$ towards an acidic condition due to the lack of $\mathrm{pH}$ buffering minerals (Figure $5 \mathrm{~b}$ ).

282 Results reported here suggest that post treatment or blending is required to correct the $\mathrm{pH}$ of the

283 RO permeate and MED distillate before beneficial consumption.

\subsection{Total organic and inorganic carbon concentration}

285 Similar to all other properties of produced water, the concentration of TOC and bicarbonate 286 varies depending from basin to basin and from one coal seam to another. Although TOC concentration in CSG produced water is generally low, their composition is often complex and their impact on the environment not very well understood [21]. TOC in natural produced water was found to consist of polycyclic aromatic hydrocarbons (PAHs), heterocyclic compounds, alkyl phenols, aromatic amines, alkyl aromatics (alkyl benzenes, alkyl biphenyls), long-chain fatty acids, and aliphatic hydrocarbons [21]. In this study, TOC concentration was as low as $1.7 \mathrm{mg} \mathrm{L}^{-1}$ and was largely unchanged after UF pre-treatment (Figure 6a). In addition, a very low rejection of TOC was also found by RO. This result indicates that the organic fraction in this CSG produced water consist of mostly small molecular weight organic compounds, which are readily permeable through low pressure RO membranes [22, 23]. On the other hand, the MED process could offer a near complete removal of TOC. Indeed, TOC in the MED distillate was consistently below the detection limit of $0.3 \mathrm{mg} / \mathrm{L}$ (Figure 5a). Unlike the RO process, MED is a phase separation process, and thus, organic removal is not dependent on their molecular weight. The results reported in Figure 5a also suggest that the organic fraction of this CSG produced water is non-volatile.

The bicarbonate concentration before and after UF, RO and MED treatment was calculated first by measuring the total inorganic carbon (i.e. TC - TOC), then using a Bjerrum plot for carbonate

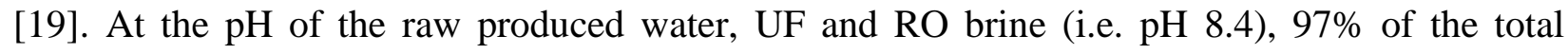
dissolved inorganic carbon exists as bicarbonate and 3\% as carbonate. On the other hand, as the $\mathrm{pH}$ of the MED brine increased to 9.6 , the ratio of bicarbonate decreased to $90 \%$ in favour of carbonate. No bicarbonate was found in the RO permeate and MED distillate (Figure 6b). Consequently, the bicarbonate concentration increased proportional with the water recovery of the process and eventually reached a concentration of $25500 \mathrm{mg} / \mathrm{L}$ in the MED brine. Results show stable rejection of both, TOC and bicarbonate throughout the study by RO and MED. 

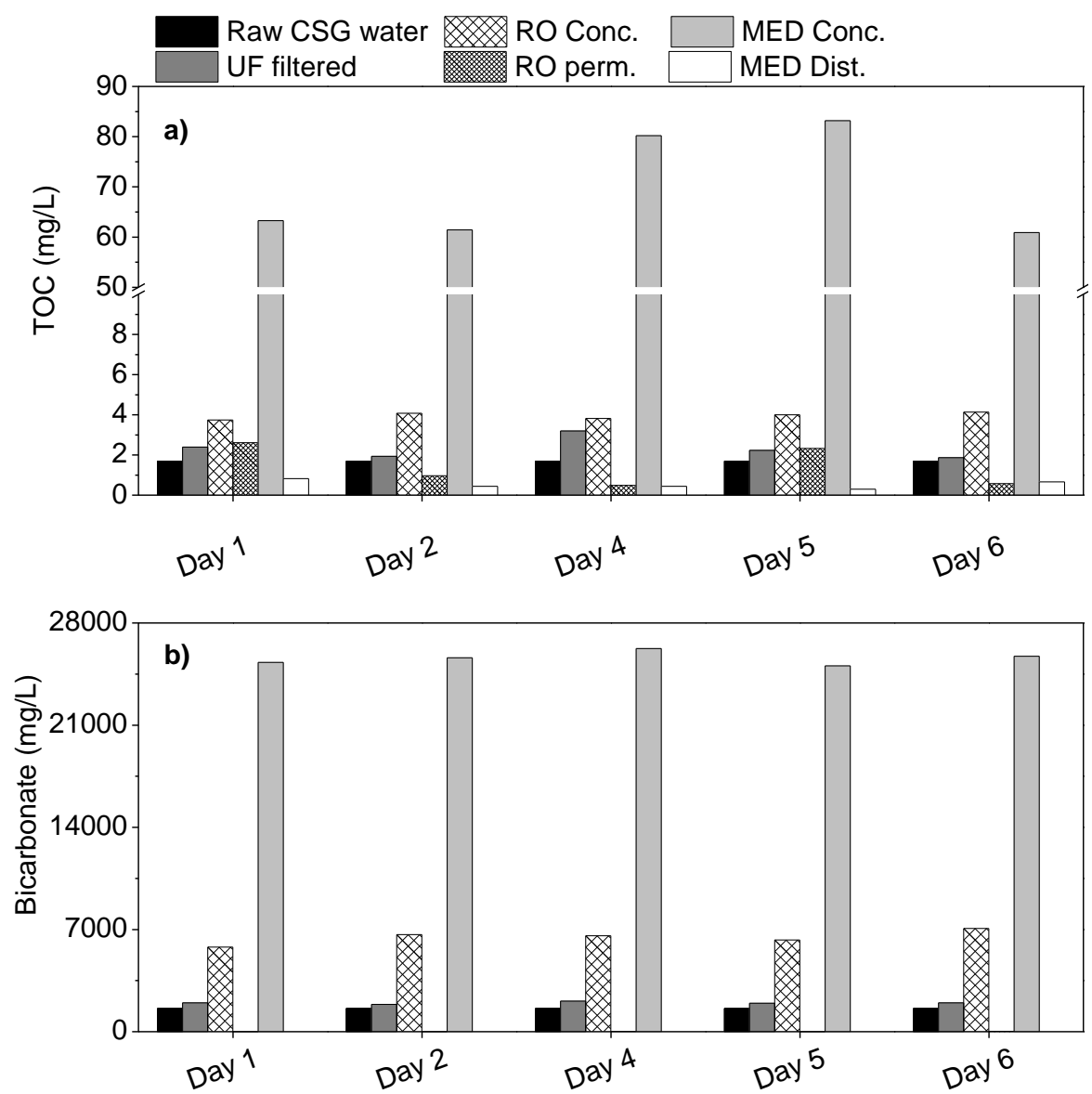

311 Figure 6: Impact of UF, RO and MED treatment on a) TOC and b) bicarbonate concentration of 312 produced water treatment over 6 successive operating days. No data on day 3 were taken.

\section{$313 \quad 3.7 \quad$ Feasibility consideration}

314 Results reported here demonstrate the technical feasibility to achieve a water recovery of $95 \%$ by 315 a combination of UF, RO, and MED treatment process over a sustained period of one week. The 316 pilot MED system used in this investigation consisted of only one evaporative chamber and was 317 not equipped with an energy recovery unit. Thus, it was not possible to evaluate the exact energy 318 consumption of the proposed treatment train. Nevertheless, MED can utilise either solar thermal 319 or waste heat from CSG compression as the primary energy source. In fact, the integration of 320 solar thermal collection with MED for brackish water desalination has been reported [24]. Such 321 solar driven MED system includes parabolic collectors (sun tracking), synthetic oil as heat 322 transfer fluid and a thermal storage system. In addition, due to the high quality of the produced 323 purified water, raw CSG produced water (i.e., UF filtrate) could be blended with the desalinated 324 water to reduce the overall energy requirement and to condition the RO permeate and MED 325 distillate. It is also noteworthy that the final MED brine obtained in this study contains enough 
sodium for the extraction of saleable minerals through membrane electrolysis. According to

327 Simon et al. [14], a sodium bicarbonate solution of $50 \mathrm{~g} / \mathrm{L}$ (which is about half its solubility limit

328 and is comparable to the strength of the MED brine obtained here) can be used as the feed stock 329 to membrane electrolysis to produce commercial grade sodium hydroxide. Using the final brine 330 as feedstock for membrane electrolysis could facilitate zero liquid discharge and at the same time 331 off-set the overall treatment cost from the sale of sodium hydroxide. Overall, the blending ratio, 332 revenue from saleable clean water and sodium hydroxide, and the availability of waste heat and 333 space for solar thermal collection will influence the operating cost of the proposed treatment 334 train. Although it is not possible to obtain a detailed economic analysis from the results 335 presented here, these factors can significantly off-set the total cost of CSG brine management.

\section{Conclusion}

337 The obtained results demonstrate the technical feasibility to treat CSG produced water by a pilot 338 treatment train of UF, RO, and MED and achieve 95\% water recovery over a sustained period. In 339 total, 12,000 L of CSG produced water was treated by the proposed treatment train. No evidence 340 of scaling and process instability associated with the RO or MED processes could be observed. 341 Indeed, detailed inspection of the evaporative chamber of the MED at the end of the experiment 342 confirmed the absence of any precipitates on the evaporative tubes. Nevertheless, mass balance 343 analysis and analytical measurement suggest that the precipitation of calcium, magnesium and 344 silica might have occurred. Indeed, mineral deposition on the sight glass of the MED evaporative 345 chamber was visible after 3 days of continuous operation. It is noteworthy that the mineral 346 deposition on the sight glass was completed removed by chemical cleaning at the end of the pilot 347 evaluation program. The desalinated water can be blended with the UF filtrate to reduce the 348 overall energy requirement of CSG produced water treatment and condition the RO permeate 349 and MED distillate for beneficial reuse.

\section{Acknowledgment}

351 This study was supported by the National Centre of Excellence in Desalination Australia, with 352 industry support from AGL Energy (Sydney, Australia), Sasakura Engineering Co., Ltd. (Osaka, 353 Japan), and OsmoFlo (Adelaide, Australia). Technical assistance from Mr Taner Ozdemir and 354 Mr Wayne Taylor (OsmoFlo) during the study is gratefully acknowledged. 


\section{References}

356 1. Hamawand, I., T. Yusaf, and S.G. Hamawand, Coal seam gas and associated water: A 357 review paper. Renewable and Sustainable Energy Reviews, 2013. 22(0): p. 550-560.

358 2. World Energy Outlook 2011: Are We Entering A Golden Age of Gas? 2011, 359 International Energy Agency: Paris. p. 1-131.

360 3. Plumlee, M.H., J.-F. Debroux, D. Taffler, J.W. Graydon, X. Mayer, K.G. Dahm, N.T. 361 Hancock, K.L. Guerra, P. Xu, J.E. Drewes, and T.Y. Cath, Coalbed methane produced water 362 screening tool for treatment technology and beneficial use. Journal of Unconventional Oil and 363 Gas Resources, 2014. 5(0): p. 22-34.

364 4. Jia, H. and J. Poinapen, Coal seam gas associated water treatment and management: 365 Opportunities and limitations. The APPEA Journal, 2013. 53: p. 185.

366 5. Stammers J, Coal Seam Gas: Issues for Consideration in the Illawarra Region, NSW, 367 Australia. 2012, University of Wollongong.

368 6. Nghiem, D.L., T. Ren, N. Aziz, I. Porter, and G. Regmi, Treatment of coal seam gas 369 produced water for beneficial use in Australia: A review of best practices. Desalination and 370 Water Treatment, 2011. 32: p. 316-323.

371 7. Dahm, K.G., K.L. Guerra, P. Xu, and J.E. Drewes, Composite Geochemical Database for 372 Coalbed Methane Produced Water Quality in the Rocky Mountain Region. Environmental 373 Science and Technology, 2011. 45(18): p. 7655-7663.

374 8. Navi, M., C. Skelly, M. Taulis, and S. Nasiri, Coal seam gas water: potential hazards and 375 exposure pathways in Queensland. International Journal of Environmental Health Research, 376 2014: p. 1-22.

377 9. Zhao, H., G.F. Vance, M.A. Urynowicz, and R.W. Gregory, Integrated treatment process 378 using a natural Wyoming clinoptilolite for remediating produced waters from coalbed natural gas 379 operations. Applied Clay Science, 2009. 42(3-4): p. 379-385.

380 10. Abousnina, R.M., L.D. Nghiem, and J. Bundschuh, Comparison between oily and coal 381 seam gas produced water with respect to quantity, characteristics and treatment technologies: a 382 review. Desalination and Water Treatment, In Press. DOI:10.1080/19443994.2014.893541. 

osmosis desalination. Desalination, 2007. 216(1-3): p. 1.

385 12. Duong, H.C., A.R. Chivas, B. Nelemans, M. Duke, S. Gray, T.Y. Cath, and L.D. Nghiem, Treatment of RO brine from CSG produced water by spiral-wound air gap membrane distillation — A pilot study. Desalination, In Press. DOI: 10.1016/j.desal.2014.10.026.

13. Coday, B.D., P. Xu, E.G. Beaudry, J. Herron, K. Lampi, N.T. Hancock, and T.Y. Cath,

The sweet spot of forward osmosis: Treatment of produced water, drilling wastewater, and other complex and difficult liquid streams. Desalination, 2014. 333(1): p. 23-35.

391 14. Simon, A., T. Fujioka, W.E. Price, and L.D. Nghiem, Sodium hydroxide production from sodium carbonate and bicarbonate solutions using membrane electrolysis: A feasibility study. Separation and Purification Technology, 2014. 127: p. 70-76.

15. Stuber, M.D., C. Sullivan, S.A. Kirk, J.A. Farrand, P.V. Schillaci, B.D. Fojtasek, and A.H. Mandell, Pilot demonstration of concentrated solar-powered desalination of subsurface agricultural drainage water and other brackish groundwater sources. Desalination, 2015. 355(0): p. 186-196.

398 16. de la Calle, A., J. Bonilla, L. Roca, and P. Palenzuela, Dynamic modeling and simulation 399 of a solar-assisted multi-effect distillation plant. Desalination, 2015. 357(0): p. 65-76.

400 17. Sardella C, Flow Testing of Craven 06 and Waukivory 03 Gas Wells. 2014, Parsons 401 Brinckerhoff.

402 18. McVicar T.R, Langhi L, Barron O.V, Rachakonda P.K, Zhang Y.Q, Dawes W.R, 403 Macfarlane C, Holland K.L, Wilkes P.G, Raisbeck-Brown N, Marvanek S.P, Li L.T, and Van 404 Niel T.G, Context statement for the Gloucester subregion. Product 1.1 from the Northern Sydney 405 Basin Bioregional Assessment. 2014, Department of the Environment, Bureau of Meteorology, 406 CSIRO, and Geoscience Australia.

407 19. Pedersen, O., T.D. Colmer, and K. Sand-Jensen, Underwater photosynthesis of 408 submerged plants - recent advances and methods. Frontiers in Plant Science, 2013. 4.

409 20. Tu, K.L., L.D. Nghiem, and A.R. Chivas, Coupling effects of feed solution pH and ionic 410 strength on the rejection of boron by NF/RO membranes. Chemical Engineering Journal, 2011. 411 168(2): p. 700-706. 
412 21. Orem, W., C. Tatu, M. Varonka, H. Lerch, A. Bates, M. Engle, L. Crosby, and J. 413 McIntosh, Organic substances in produced and formation water from unconventional natural gas 414 extraction in coal and shale. International Journal of Coal Geology, 2014(0).

415 22. Bellona, C., J.E. Drewes, P. Xu, and G. Amy, Factors affecting the rejection of organic 416 solutes during NF/RO treatment - a literature review. Water Research, 2004. 38(12): p. 27954172809.

418 23. Nghiem, L.D. and P.J. Coleman, NF/RO filtration of the hydrophobic ionogenic 419 compound triclosan: Transport mechanisms and the influence of membrane fouling. Separation 420 and Purification Technology, 2008. 62(3): p. 709-716.

421 24. Milow, B. and E. Zarza, Advanced MED solar desalination plants. Configurations, costs, 422 future - seven years of experience at the Plataforma Solar de Almeria (Spain). Desalination, 423 1997. 108(1-3): p. 51-58. 